\title{
Coronary artery bypass grafting with or without cardiopulmonary bypass in patients with preoperative non-dialysis dependent renal insufficiency: A randomized study
}

Lokeswara Rao Sajja, MCh, FACS, ${ }^{a}$ Gopichand Mannam, FRCS (Ed), FRCS (CT), ${ }^{a}$

Rajasekara M. Chakravarthi, MD, DNB, ${ }^{\mathrm{b}}$ Sriramulu Sompalli, MD, ${ }^{\mathrm{c}}$ Shanti K. Naidu, MD, ${ }^{\mathrm{d}}$

Bhupathiraju Somaraju, MD, DM, ${ }^{e}$ and Raghava Raju Penumatsa, MD, DM ${ }^{e}$

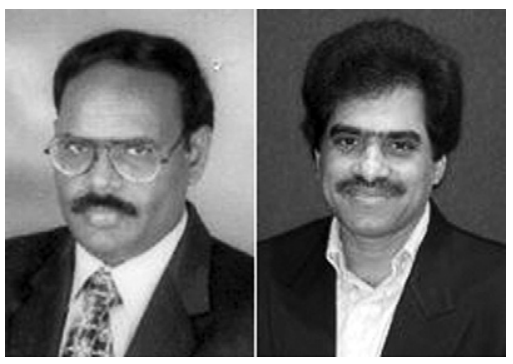

Drs Sajja and Mannam (left to right)

丹 Supplemental material is available online.
From the Divisions of Cardiothoracic Surgery, ${ }^{\mathrm{a}}$ Nephrology, ${ }^{\mathrm{b}}$ Cardiac Anesthesiology, ${ }^{\mathrm{c}}$ Biochemistry, ${ }^{\mathrm{d}}$ and Cardiology, ${ }^{\mathrm{e}}$ CARE Hospital, The Institute of Medical Sciences, Hyderabad, India.

Read at the Eighty-sixth Annual Meeting of The American Association for Thoracic Surgery, Philadelphia, Pa, April 29-May 3, 2006.

Received for publication April 11, 2006; revisions received Aug 19, 2006; accepted for publication Sept 28, 2006.

Address for reprints: G. Mannam, FRCS (CT), CARE Hospitals, The Institute of Medical Sciences, Hyderabad-500034, India (E-mail: gopi.mannam@gmail.com).

J Thorac Cardiovasc Surg 2007;133:378-88 $0022-5223 / \$ 32.00$

Copyright (๑) 2007 by The American Association for Thoracic Surgery

doi:10.1016/j.jtcvs.2006.09.028
Objective: Preoperative renal insufficiency is a predictor of acute renal failure in patients undergoing coronary artery revascularization with cardiopulmonary bypass. Off-pump coronary artery bypass grafting has been shown to be less deleterious than on-pump bypass in patients with normal renal function, but the effect of this technique in patients with nondialysis dependent renal insufficiency in a randomized study is unknown.

Methods: From August 2004 through October 2005, 116 consecutive patients with preoperative non-dialysis-dependent renal insufficiency (glomerular filtration rate measured using the Modification of Diet in Renal Disease equation [MDRD GFR] $\leq 60 \mathrm{~mL} \cdot \mathrm{min}^{-1} \cdot 1.73$ $\mathrm{m}^{-2}$ ) undergoing primary coronary artery bypass grafting were randomized to on-pump (n $=60)$ and off-pump $(\mathrm{n}=56)$ groups. MDRD GFR and serum creatinine levels were measured preoperatively and postoperatively at days 1 and 5 . The changes in renal function and clinical outcomes were compared between the two groups.

Results: Preoperative characteristics were comparable between the two groups. The repeated-measures analysis of variance was performed on the data that showed worsening of renal function in the on-pump group compared with the off-pump group (serum creatinine, $P<.000$; glomerular filtration rate, $P<.000)$. Further analysis of subgroups of patients with diabetes alone, hypertension alone, and combined hypertension and diabetes also showed significant deterioration renal function in the on-pump group compared with the off-pump group. In covariate analysis, diabetes has emerged as a significant covariate by serum creatinine criteria while compromised left ventricular function has emerged as a significant covariate by glomerular filtration rate criteria. These analyses showed that the use of cardiopulmonary bypass is significantly associated with adverse renal outcome $(P<.000)$. Three patents required hemodialysis in the on-pump group and none in the off-pump group. The mean number of grafts per patient was $3.85 \pm$ 0.86 and $3.11 \pm 0.89$ in the on-pump and off-pump groups, respectively $(P<.001)$, but the indices of completeness of revascularization, $1.00 \pm 0.08$ for off-pump coronary bypass and $1.01 \pm 0.08$ for on-pump coronary bypass, were similar $(P=.60)$.

Conclusions: This study suggests that on-pump as compared with off-pump coronary artery bypass grafting is more deleterious to renal function in diabetic patients with non-dialysis dependent renal insufficiency. MDRD GFR is a more sensitive investigation than serum creatinine levels to assess renal insufficiency in patients undergoing coronary bypass.

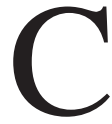
ardiac operations with cardiopulmonary bypass (CPB) adversely affect renal function, causing varying degrees of postoperative renal impairment. Postoperative renal failure remains a serious complication of cardiac surgery, although the incidence of acute renal failure (ARF) necessitating dialysis after cardiac operations is relatively low $(1 \%-5 \%) \cdot{ }^{1-4}$ It is associated with increased 


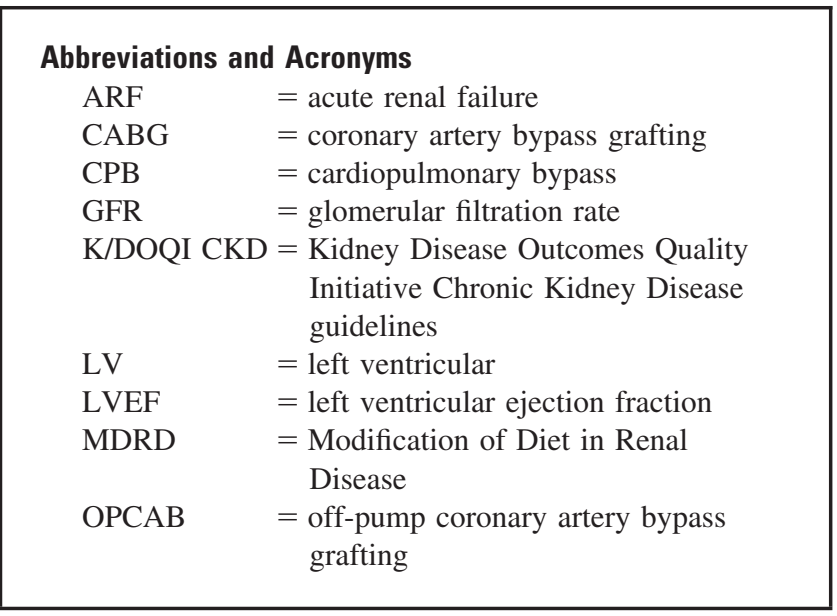

mortality, morbidity, and intensive care unit stay, particularly if there is a requirement for hemodialysis. ${ }^{5-8}$ The precise level at which renal dysfunction begins is unknown. Clinical impression suggests that even mild or moderate elevation of serum creatinine levels has an adverse effect on outcome. ${ }^{9}$ The results of the study by Durmaz and colleagues ${ }^{10}$ suggest that even those patients with relatively mild renal insufficiency remain at risk for a poor outcome. In patients with creatinine levels higher than $2.5 \mathrm{mg} / \mathrm{dL}$, there is a strong likelihood of needing postoperative dialysis besides increased risks of mortality and morbidity. Several studies have assessed the risk associated with mild to moderate renal insufficiency in patients undergoing coronary artery bypass grafting (CABG) ${ }^{10-12}$ However, in these studies renal function has been defined according to the levels of serum creatinine and not by calculated creatinine clearance or glomerular filtration rate (GFR). Because serum creatinine concentration is affected by several factors other than the filtration of creatinine, calculated creatinine clearance or GFR provides a more accurate estimate of renal function. ${ }^{13}$ The effect of off-pump CABG (OPCAB) on postoperative renal impairment has also been controversial. Although it has been reported that OPCAB may minimize renal injury in elective patients with normal and impaired preoperative renal function and in high-risk patients, ${ }^{14-18}$ other studies have failed to show such benefit. ${ }^{19-22}$ However, there had been no published data from randomized studies of patients with non-dialysis-dependent renal insufficiency undergoing CABG with or without CPB. In this randomized study, we evaluated the effect of off-pump and on-pump techniques on renal function assessed by serum creatinine and GFR in patients with preoperative non-dialysis-dependent renal insufficiency undergoing primary CABG.

\section{Patients and Methods}

\section{Patient Enrollment and Random Assignment}

This study was designed to compare the effect of off-pump and on-pump techniques on renal function in patients with non- dialysis-dependent renal insufficiency with a GFR of $60 \mathrm{~mL}$. $\min ^{-1} \cdot 1.73 \mathrm{~m}^{-2}$ or less undergoing primary, elective CABG. In an effort to minimize variability, all the procedures were performed by two surgeons (G.M., L.R.S.) experienced in OPCAB surgery and all patient management was conducted by a single team according to strict, unbiased, criteria-driven protocols. After approval by the institutional review board and informed consent, a total of 120 patients requiring primary CABG at CARE Hospital, Banjara Hills, Hyderabad, India, were enrolled to the study between August 3, 2004 (first patient) and September 26, 2005 (116th patient) and were randomized, 60 patients each, to withCPB or without-CPB groups by a computer-generated random number table. This was done for each patient after the operating surgeon had documented the intended revascularization to be performed, which was based on review of the preoperative coronary angiogram. Random assignment was not stratified by diabetic status, hypertension, or compromised left ventricular (LV) function. Four of these patients ( 2 were found to require mitral valve repair, 1 patient needed emergency CABG because of unstable angina, and 1 patient did not report for surgery) dropped out after random assignment and were subsequently excluded from the study. All 4 of these patients belonged to the off-pump group. Hence, the total number of intent-to-treat population was 116 patients (on-pump group, $\mathrm{n}=60$; off-pump group, $\mathrm{n}=56$.).

\section{Methods}

A standard set of perioperative data were collected prospectively for all patients: age, sex, height, weight, diabetes mellitus, hypertension, peripheral vascular disease, LV ejection fraction (LVEF), number of significantly stenosed coronary arteries, prior myocardial infarction, angina class, serum creatinine, and GFR measured using the equation of the Modification of Diet in Renal Disease (MDRD) study. All patients in both groups received $600 \mathrm{mg}$ of $\mathrm{N}$-acetylcysteine orally once daily immediately before revascularization and for the first 5 postoperative days. None of the patients received aminoglycosides or nonsteroidal anti-inflammatory agents perioperatively. Two patients in the on-pump group received aprotinin 500,000 KIU in the postoperative period because of excessive mediastinal bleeding due to generalized oozing; the other patients in the study did not receive any antifibrinolytics. Postoperatively, whole blood or packed red blood cells were transfused for all patients whose hemoglobin value was less than 9 $\mathrm{gm} / \mathrm{dL}$.

\section{Renal Function}

Serum creatinine levels and GFRs were measured at the time of hospitalization and postoperatively on day 1 and day 5 . The GFR was measured with the MDRD equation. Renal insufficiency was defined according to the guidelines from the National Kidney Foundation. ${ }^{23}$ The Kidney Disease Outcomes Quality Initiative Chronic Kidney Disease (K/DOQI CKD) guidelines have established a 5-stage classification of patients with chronic kidney disease that is based solely on kidney function. These stages are defined by a GFR greater than or equal to $90 \mathrm{~mL} \cdot \mathrm{min}^{-1}$. $1.73 \mathrm{~m}^{-2}$ (stage 1 ), 60 to $89 \mathrm{~mL} \cdot \min ^{-1} \cdot 1.73 \mathrm{~m}^{-2}$ (stage 2 ), 30 to $59 \mathrm{~mL} \cdot \min ^{-1} \cdot 1.73 \mathrm{~m}^{-2}$ (stage 3 ), 15 to $29 \mathrm{~mL} \cdot \min ^{-1}$. $1.73 \mathrm{~m}^{-2}$ (stage 4 ), and less than $15 \mathrm{~mL} \cdot \min ^{-1} \cdot 1.73 \mathrm{~m}^{-2}$ 
(stage 5). Acute renal dysfunction was classified on the basis of RIFLE criteria. ${ }^{24}$

\section{Estimation of GFR by MDRD Equation}

GFR was measured by the MDRD formula. ${ }^{23}$ The variables included were age, sex, height in centimeters, and weight in kilograms for body surface area calculation, blood urea nitrogen (BUN), serum creatinine (Scr), and serum albumin (Alb). The formula used is as follows.

$$
\begin{aligned}
& \text { GFR }\left(\mathrm{mL} \cdot \mathrm{min}^{-1} \cdot 1.73 \mathrm{~m}^{2}\right)= \\
& 170 \times(\mathrm{Scr})^{-0.999} \times(\text { Age })^{-0.716} \times(\mathrm{BUN})^{-0.070} \times(\mathrm{Alb})^{+0.318} \\
& \quad \text { for male subjects } \\
& 170 \times(\mathrm{Scr})^{-0.999} \times(\text { Age })^{-0.716} \times(\mathrm{BUN})^{-0.070} \times(\mathrm{Alb})^{+0.318} \\
& \quad \times(0.762) \text { for female subjects }
\end{aligned}
$$

(See additional text online.*)

\section{Surgical Technique}

General. The surgical techniques were followed as described earlier. $^{25}$ Surgical access to the heart was through a standard median sternotomy in all patients.

(See additional text online. ${ }^{\dagger}$ )

On-pump technique. $\mathrm{CPB}$ was instituted with ascending aorta cannulation and 2-stage venous cannulation of the right atrium. A standard circuit made of polyvinyl chloride tubing (Lifeline Systems Pvt Ltd, New Delhi. India), which included a 40- $\mu$ m filter, and a Sarns 8000 (Terumo Cardiovascular Systems Corporation, Ann Arbor, Mich) heart-lung machine and a hollow-fiber membrance oxygenator (Affinity NT, Medtronic Inc, Minneapolis, Minn) were used. The extracorporeal circuit was prepared with $1000 \mathrm{~mL}$ of Ringer's lactate, $500 \mathrm{~mL}$ of hydroxyethyl starch $6 \%$, $0.5 \mathrm{~g} / \mathrm{kg}$ of mannitol, $10 \mathrm{~mL}$ of $10 \%$ calcium gluconate, $25 \mathrm{~mL}$ of sodium bicarbonate IP $7.5 \% \mathrm{w} / \mathrm{v}$, and $5000 \mathrm{IU}$ of heparin. Nonpulsatile flow was used. Flow throughout bypass was $2.4 \mathrm{~L} \cdot \mathrm{m}^{-2}$ - $\min ^{-1}$ and mean perfusion pressure was maintained between 60 and $70 \mathrm{~mm} \mathrm{Hg}$ by adjusting the doses of nitroglycerine and phenylephrine/dobutamine/norepinephrine. The conventional CABG with CPB was accomplished with every effort made to minimize the impact of $\mathrm{CPB}$. Intraoperative ultrafiltration was not used. Systemic temperature was kept between $32^{\circ} \mathrm{C}$ and $36^{\circ} \mathrm{C}$. Myocardial protection was achieved with intermittent ischemic fibrillatory arrest or intermittent antegrade hyperkalemic cold blood cardioplegic arrest based on the operating surgeon's preference of technique of myocardial protection. The proximal anastomoses were performed with partial clamping of the ascending aorta, as soon as one distal anastomosis was completed (intermittent ischemic arrest technique) or after completion of all distal anastomoses (blood cardioplegic technique).

OPCAB technique. The method of exposure and stabilization to perform the anastomoses consisted of the technique previously described by our group. ${ }^{25}$ OPCAB was performed with the Medtronic Octopus 3 or 4 (Medtronic, Inc, Minneapolis, Minn) stabilizing device for target coronary artery stabilization. Target arteries were accessed either by deep pericardial traction sutures or by the use of a Medtronic Starfish cardiac positioner (Medtronic,

*RIFLE $=$ Risk, Injury, Failure, Loss, ESRD (end-stage renal disease).
Inc). A mean systemic arterial pressure was maintained around 65 to $70 \mathrm{~mm} \mathrm{Hg}$ throughout the procedure. An intracoronary shunt (Medtronic, Inc, Grand Rapids, Mich) was used in all vessels measuring more than $1.25 \mathrm{~mm}$ in diameter while constructing the coronary anastomosis. Visualization of the anastomotic area was enhanced by using a humidified carbon dioxide blower/mister (Medtronic, Inc, Grand Rapids, Mich) to disperse the blood from the anastomotic site while constructing the distal anastomoses. For safety, a CPB machine was kept with the circuit mounted, but not primed.

(See additional text online. $^{\dagger}$ )

\section{Statistical Analysis}

Statistical analysis was done with SPSS 11.5 for Windows (SPSS, Inc, Chicago, Ill). The proportions of baseline events in the two treatment groups were compared by the $\chi^{2}$ test and the means by the 2 -sample independent $t$ test at $P<.05$. For the primary evaluation, deterioration in renal function in patients with nondialysis-dependent renal insufficiency undergoing primary CABG, as measured by a rise in serum creatinine/fall in GFR by $20 \%$ or more of preoperative values, was compared between groups with and without $\mathrm{CPB}$. The proportions were compared and at $P<.05$ considered to be statistically significant. Repeated-measures analysis of variance was used to investigate the effect of CPB on renal function during surgery. The analysis was performed on logtransformed variables and untransformed variables. A $P$ value less than .05 was considered as significant to test the null hypothesis that there is no difference between groups. Number of patients studied was considered to be sufficient if a power of 0.8 in repeated-measures analysis is observed both for main effects and for interaction. Subgroup analysis was undertaken to study the $\mathrm{CPB}$ effect in specific categories of groups. Covariates were introduced in repeated-measures analysis to study the effect of covariates at $P<.05$.

\section{Results}

\section{Analysis of Baseline Characteristics}

Baseline and intraoperative characteristics are shown in Table 1. The two groups were similar with respect to age, gender, diabetes mellitus, hypertension, smoking, angina class, preoperative cerebrovascular accident, and LVEF. There was no statistically significant difference in preoperative serum creatinine and MDRD GFR levels between the two groups ( $P=.477, P=.774)$. Mean number of grafts per patient was $3.85 \pm 0.86$ and $3.11 \pm 0.89$ in on-pump and off-pump groups, respectively $(P<.001)$, but there was no statistically significant difference in the index of completeness of revascularization: $1.01 \pm 0.08$ versus $1.00 \pm$ $0.01(P=.60)$. There was no conversion of off-pump to on-pump technique in this study.

\section{Morbidity Analysis}

Patients in the on-pump group showed a higher requirement for inotropic use $(P=.043)$ and blood transfusion $(P<$ .001). Blood loss was higher in the on-pump group than in the off-pump group $(P<.001)$. The intubation time for the 
TABLE 1. Baseline characteristics of intent-to-treat population

\begin{tabular}{lccc}
\hline Characteristics & $\begin{array}{c}\text { Without CPB } \\
(\mathbf{n}=\mathbf{5 6})\end{array}$ & $\begin{array}{c}\text { With CPB } \\
(\mathbf{n}=\mathbf{6 0})\end{array}$ & $\boldsymbol{P}$ value \\
\hline Age (y) & & & \\
$\quad$ Mean & 60.0 & 60.50 & .72 \\
$\quad$ SD & 8.43 & 7.87 & \\
Male (\%) & $49(87.5)$ & $54(90.0)$ & .67 \\
Female (\%) & $7(12.5)$ & $6(10.0)$ & \\
LV function (LVEF $\leq 49 \%)$ & 42.9 & 41.7 & .20 \\
Diabetes (\%) & 58.9 & 53.3 & .54 \\
Hypertension (\%) & 66.1 & 76.7 & .21 \\
Smokers (\%) & 37.5 & 43.3 & .52 \\
Angina class & & & \\
$\quad$ II & 26.8 & 20.0 & \\
$\quad$ III & 58.9 & 63.3 & .68 \\
$\quad$ IV & 14.3 & 16.7 & \\
Serum creatinine preop & & & \\
$\quad$ Mean & 1.414 & 1.482 & .47 \\
$\quad$ SD & 0.5482 & 0.5482 & \\
GFR preop & & & \\
$\quad$ Mean & & \\
SD & 52.01 & 51.66 & .83 \\
\hline
\end{tabular}

$\overline{P \text { value }>.05 \text { is statistically not significant. } C P B \text {, Cardiopulmonary bypass; }}$ $G F R$, glomerular filtration rate; $L V$, left ventricular; $L V E F$, left ventricular ejection fraction; Preop, preoperative; $S D$, standard deviation.

on-pump group was significantly higher than that for the off-pump group: $9.32 \pm 6.64$ hours versus $5.55 \pm 2.28$ hours $(P<.001)$. Three patients in the on-pump group required hemodialysis compared with none in the off-pump group. There was no statistically significant difference in the incidence of postoperative cerebrovascular accident (Table 2).

\section{Analysis of Changes in Serum Creatinine Levels and GFR}

Having known the effect of a mild to moderate increase in the preoperative serum creatinine level on outcome, we analyzed the changes in serum creatinine levels after CABG using univariate and multivariate analyses. In the present study, we found that 35 of $116(30 . \%)$ patients had normal renal function by serum creatinine criteria $(\leq 1.29 \mathrm{mg} / \mathrm{dL})$ and were in stage 3 of chronic kidney disease by GFR criteria (GFR $\leq 60 \mathrm{~mL} \cdot \min ^{-1} \cdot 1.73 \mathrm{~m}^{-2}$ ). In the intentto-treat population, the elevation of serum creatinine level at postoperative days 1,5 , and 15 in the on-pump group was statistically significant compared with the off-pump group $(P<.001)$, as shown in Figure 1, $a$, and Tables 3A and 3B. increase in serum creatinine level after CABG by $20 \%$ or more over the preoperative value was taken as an important elevation and occurred in $39(62 \%)$ of 60 patients in the on-pump group compared with 17 (30\%) of 56 patients in the off-pump group $(P<.000){ }^{12}$ The fall in GFR at postoperative days 1 and 5 in the CPB group was statisti-
TABLE 2. Postoperative clinical outcomes

\begin{tabular}{lccc}
\hline Variable & Without CPB & With CPB & $P$ value \\
\hline Inotropic requirement & $26(46)$ & $40(67)$ & .043 \\
$\begin{array}{l}\text { Blood transfusion } \\
\quad \text { (units/patient) }\end{array}$ & $0.77 \pm 0.85$ & $1.88 \pm 0.71$ & $<.001$ \\
Chest tube drainage (mL) & $360 \pm 109$ & $542 \pm 161$ & $<.001$ \\
Postop dialysis & 0 & 3 & - \\
Deaths & 0 & 3 & - \\
CVA & 0 & 1 & - \\
Mean number of grafts/patient & $3.11 \pm 0.89$ & $3.85 \pm 0.86$ & $<.001$ \\
IOCR & $1.00 \pm 0.08$ & $1.01 \pm 0.08$ & .60 \\
Intubation time (h) & $5.55 \pm 2.28$ & $9.32 \pm 6.64$ & $<.001$
\end{tabular}

$C P B$, Cardiopulmonary bypass; $C V A$, cerebrovascular accident; $I O C R$, index of completeness of revascularization.

cally significant compared with the off-pump group $(P<$ .007) (Figure 1, $a$, and Tables 3A and 3B).

A fall in GFR after CABG by $20 \%$ or more of the preoperative value was taken as an important fall and occurred in $33(55.0 \%)$ of 60 patients in the on-pump group compared with 17 (30.4\%) of 56 patients in off-pump group $(P<.007)$.

\section{Analysis of Subset of Patients With Diabetes}

Twenty-seven $(84 \%)$ of 32 patients with diabetes in the on-pump group and 16 (49\%) of 33 patients with diabetes in the off-pump group had an elevation of $20 \%$ or more in serum creatinine over their preoperative values $(P<.002)$ (Tables 3A and E1). Eighteen (56\%) of 32 patients with diabetes in the on-pump group and $12(36 \%)$ of 33 patients with diabetes in the off-pump group had a $20 \%$ or greater fall in GFR over their preoperative values, which did not reach statistical significance $(P<.108)$ (Tables $3 \mathrm{~A}$ and E1). This $20 \%$ fall in GFR may not have reached conventional statistical significance, but it is still a clinically important difference and may reflect that this study was underpowered to detect statistically significant differences in the fall of GFR of $20 \%$ with both techniques. However, in means and repeated-measures analysis, on-pump patients showed significant deterioration in renal function by both serum creatinine and GFR criteria $(P<.000)$ (Table E1).

\section{Analysis of Subset of Patients With Hypertension}

Thirty (63\%) of 46 patients who were hypertensive in the on-pump group and 13 (35\%) of 37 patients who were hypertensive in the off-pump group showed a $20 \%$ elevation or greater of serum creatinine over their preoperative values $(P<$ .011) (Tables 3A and E2).

Twenty-six (56.5\%) of 46 patients who were hypertensive in the on-pump group and 12 (32\%) of 37 patients who were hypertensive in the off-pump group showed a $20 \%$ fall or 

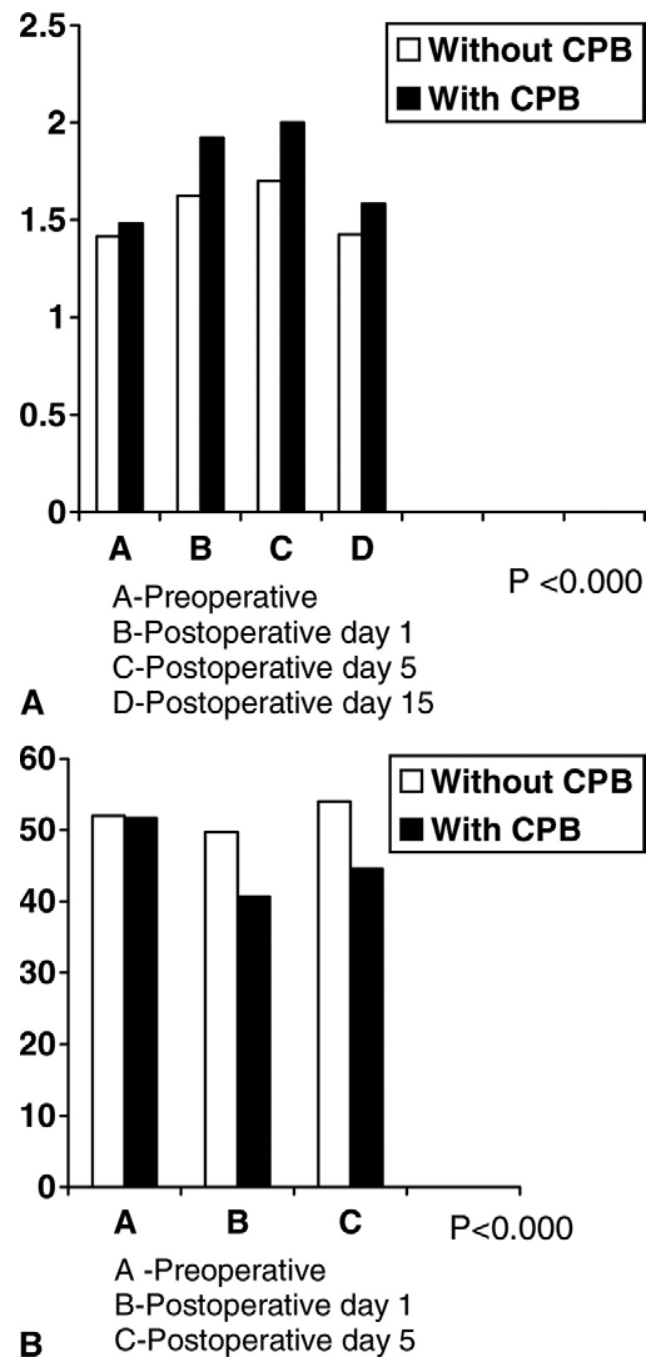

Figure 1. A, Serum creatinine levels preoperatively $(A)$ and on postoperative days $1(B), 5(C)$, and $15(D)$ in patients undergoing CABG with CPB and without CPB $(P<.001)$. B, MDRD GFR preoperatively $(A)$ and on postoperative days $1(B)$ and $5(C)$ in patients undergoing CABG with or without CPB $(P<.007)$.

greater in GFR over their preoperative value $(P<.029)$ (Tables 3A and E2).

\section{Dysfunction}

The rise in serum creatinine in patients with fair or poor LV function ( $\mathrm{LVEF} \leq 49 \%$ ) was greater in the CPB group than in the OPCAB group, but the rise did not reach statistical significance $(P<.100)$ and the fall in GFR was statistically significant in the CPB group compared with the OPCAB group $(P<$ .0.32) (Table 3A).

Means and repeated-measures analysis of results of preoperative and postoperative levels of serum creatinine and GFR showed elevation of serum creatinine and fall of GFR values in both groups (with $\mathrm{CPB}$ and without $\mathrm{CPB}$ ). The inspection of means and geometric means of the overall intent-to-treat population showed that the on-pump group had higher postoperative values than the off-pump group at all points of time, although the baseline values were similar (serum creatinine, $P$ $<$.000; GFR, $P<.000$; Table 3B). The analysis was also done for the subsets of patients with diabetes and hypertension, which showed statistically significant deterioration in renal function by both serum creatinine and GFR criteria in the on-pump group (diabetes, $P<.000$; hypertension, $P<.000$; Tables E1 and E2).

The direct effects of inotropic use, blood transfusion, intubation time, and presence of diabetes mellitus, hypertension, and compromised LV function (LVEF $\leq 49 \%$ ) on renal outcomes as measured by serum creatinine and MDRD GFR are studied, introducing all the above variables as covariates in the repeated-measures analysis. The analysis shows that diabetes mellitus has emerged as a significant covariate by serum creatinine criteria and compromised LV function has emerged as a significant covariate by GFR criteria (Tables 4A and 4B). All other covariables (hypertension, blood transfusion, inotropic use, and intubation time) were found to be statistically not significant $(P>.05)$. In both the analyses, use of $\mathrm{CPB}$ is significantly associated with adverse renal outcome $(\mathrm{P}<.000)$. The observed power is sufficiently high and hence the sample is sufficient to draw valid conclusions.

Analysis of Postoperative Changes in Serum Creatinine and GFR in Subset of Patients With Preoperative Normal Serum Creatinine $(\leq 1.29 \mathrm{mg} / \mathrm{dL})$ and Decreased GFR $\left(\leq 60 \mathrm{~mL} \cdot \mathrm{min}^{-1} \cdot 1.73 \mathrm{~m}^{-2}\right)$.

This subgroup of patients was analyzed for changes in postoperative renal function. There was significant rise in serum creatinine levels in the CPB group compared with the offpump group $(P=.002)$, but there was no statistically significant further fall in GFR between the two groups $(P=.108)$.

\section{Mortality Analysis}

Three deaths occurred in the on-pump group and no deaths in the off-pump group $(P=.09)$. The 3 patients who died had preoperative serum creatinine values of $0.9,2.1$, and 1.7 $\mathrm{mg} / \mathrm{dL}$ and GFR values of 48.12, 31.59, and $46.52 \mathrm{~mL}$. $\min ^{-1} \cdot 1.73 \mathrm{~m}^{-2}$, respectively. There was a fall in GFR on the first postoperative day in all 3 patients, and GFR values were $39.18,25.15$, and $25.16 \mathrm{~mL} \cdot \min ^{-1} \cdot 1.73 \mathrm{~m}^{-2}$, respectively. There was a rise in serum creatinine on the first postoperative day and the values were 1.6, 2.6, and 2.3 $\mathrm{mg} / \mathrm{dL}$ respectively. Two patients who had postoperative ARF had fair LV function and 1 patient had good LV function.

All patients who had ARF postoperatively were aged 62 years and above. 
TABLE 3A. Deterioration in renal function as measured by rise in serum creatinine/fall in GFR by $20 \%$ or more of preoperative values

\begin{tabular}{|c|c|c|c|c|c|c|}
\hline \multirow[b]{2}{*}{ Population } & \multirow[b]{2}{*}{ Variable } & \multicolumn{2}{|c|}{ Without CPB } & \multicolumn{2}{|c|}{ With CPB } & \multirow[b]{2}{*}{$P$ value } \\
\hline & & $\mathbf{N}$ & $\%$ & $\mathbf{N}$ & $\%$ & \\
\hline \multirow[t]{2}{*}{ ITT } & Serum creatinine & 56 & 30.4 & 60 & 61.7 & $<.001$ \\
\hline & GFR & 56 & 30.4 & 60 & 55.0 & $<.007$ \\
\hline \multirow[t]{2}{*}{ Diabetes } & Serum creatinine & 33 & 48.5 & 32 & 84.4 & $<.002$ \\
\hline & GFR & 33 & 36.4 & 32 & 56.3 & $<.108$ \\
\hline \multirow[t]{2}{*}{ Hypertension } & Serum creatinine & 37 & 35.1 & 46 & 63.0 & $<.011$ \\
\hline & GFR & 37 & 32.4 & 46 & 56.5 & $<.029$ \\
\hline \multirow[t]{2}{*}{ Diabetes + hypertension } & Serum creatinine & 23 & 52.2 & 27 & 85.2 & $<.011$ \\
\hline & GFR & 23 & 43.5 & 27 & 59.3 & $<.266$ \\
\hline \multirow[t]{2}{*}{ Fair or poor LV function } & Serum creatinine & 24 & 29.2 & 25 & 52.0 & $<.100$ \\
\hline & GFR & 24 & 37.5 & 25 & 68.0 & $<.032$ \\
\hline \multirow[t]{2}{*}{ Patients who did not require inotropes } & Serum creatinine & 30 & 23.3 & 20 & 75.0 & $<.001$ \\
\hline & GFR & 30 & 63.3 & 20 & 40.0 & $<.105$ \\
\hline
\end{tabular}

$P$ value $<.05$ is statistically significant. $C P B$, Cardiopulmonary bypass; GFR, glomerular filtration rate; ITT, intent-to-treat; $L V$, left ventricular.

Only 1 patient was diabetic and none was hypertensive among the deceased. The cause of death in all 3 patients was postoperative ARF.

\section{Discussion}

Postoperative ARF in patients undergoing CABG has been associated with high morbidity and mortality. ${ }^{1-4}$ The bench- mark study conducted by Chertow and colleagues ${ }^{5}$ reported a mortality of $63 \%$ at 30 days for those patients requiring hemodialysis compared with $4.3 \%$ for those without renal dysfunction. A more recent work by Mangano and associates ${ }^{7}$ identified similar mortality rates among patients with postoperative renal failure. Baseline renal impairment has been consistently identified as a major predictor for postop-

TABLE 3B. Means and repeated-measures analysis of results of preoperative and postoperative values

\begin{tabular}{|c|c|c|c|c|c|c|c|}
\hline \multirow[b]{2}{*}{ CPB } & \multirow[b]{2}{*}{$\mathbf{N}$} & \multirow[b]{2}{*}{ Mean } & \multirow[b]{2}{*}{ SD } & \multirow[b]{2}{*}{ Geometric mean } & \multicolumn{3}{|c|}{ ANOVA results } \\
\hline & & & & & Significant effect Power & $\mathbf{F}$ & $\boldsymbol{P}$ \\
\hline \multicolumn{8}{|l|}{ S. creatinine preop } \\
\hline Without CBP & 56 & 1.414 & .4342 & 1.366 & & & \\
\hline With CBP & 60 & 1.482 & .5482 & 1.416 & & & \\
\hline \multicolumn{8}{|l|}{ S. creatinine POD 1} \\
\hline Without CBP & 56 & 1.623 & .4411 & 1.579 & & & \\
\hline With CBP & 60 & 1.922 & .7529 & 1.833 & & \multirow{4}{*}{$\begin{array}{c}59.52 \\
3.889\end{array}$} & \multirow{4}{*}{$\begin{array}{l}<.0001 .000 \\
<.0040 .833\end{array}$} \\
\hline S. creatinine POD 5 & & & & & \multirow{3}{*}{$\begin{array}{l}\text { Time } \\
\text { CPB } \times \text { time }\end{array}$} & & \\
\hline Without CBP & 56 & 1.700 & .7234 & 1.595 & & & \\
\hline With CBP & 60 & 2.001 & .9082 & 1.861 & & & \\
\hline \multicolumn{8}{|l|}{ S. creatinine POD 15} \\
\hline Without CBP & 56 & 1.425 & .4140 & 1.387 & & & \\
\hline With CBP & 60 & 1.582 & .5410 & 1.511 & & & \\
\hline \multicolumn{8}{|l|}{ MDRD GFR preop } \\
\hline Without CBP & 56 & 52.014 & 8.6072 & 51.101 & & & \\
\hline With CBP & 60 & 51.662 & 9.3451 & 50.502 & & & \\
\hline \multicolumn{8}{|l|}{ MDRD GFR POD 1} \\
\hline Without CBP & 56 & 49.6804 & 14.73726 & 47.0888 & Time & 35.707 & $<.0001 .000$ \\
\hline With CBP & 60 & 40.6973 & 14.62146 & 38.1746 & $\mathrm{CPB} \times$ time & 13.808 & $<.0000 .998$ \\
\hline \multicolumn{8}{|l|}{ MDRD GFR POD 5} \\
\hline Without CBP & 56 & 53.9632 & 10.74941 & 52.8838 & & & \\
\hline With CBP & 60 & 44.6200 & 12.47290 & 42.9257 & & & \\
\hline
\end{tabular}

The log-transformed serum creatinine/GFR values were subjected to statistical analysis using repeated-measures analysis of variance. $C P B$, Cardiopulmonary bypass; MDRD GFR, modification of diet in renal diseases equation glomerular filtration rate; $P O D$, postoperative day; Time, changes with duration of time during postoperative period; $C P B \times$ time, interaction of the procedure with or without $C P B \times$ time; $S D$, standard deviation. 
TABLE 4A. Multivariate tests for changes in serum creatinine levels

\begin{tabular}{|c|c|c|c|c|c|c|}
\hline Effect & Value & $\mathbf{F}$ & Hypothesis $d f$ & Error $d f$ & Sig. & Observed power ${ }^{\mathrm{a}}$ \\
\hline Pillai's trace & .074 & $2.868^{b}$ & 3 & 107 & .040 & .672 \\
\hline Pillai's trace & .308 & $15.896^{\mathrm{b}}$ & 3 & 107 & .000 & 1.000 \\
\hline \multicolumn{7}{|c|}{ Factor $1 *$ hypertension } \\
\hline $\begin{array}{c}\text { Pillai's trace } \\
\text { Factor } 1 * \text { intub }\end{array}$ & .020 & $.725^{\mathrm{b}}$ & 3 & 107 & .540 & .200 \\
\hline \multicolumn{7}{|c|}{ Factor $1 *$ blood transfusion } \\
\hline Pillai's trace & .024 & $.895^{\mathrm{b}}$ & 3 & 107 & .447 & .240 \\
\hline \multicolumn{7}{|c|}{ Factor $1 *$ compromised LV function } \\
\hline Pillai's trace & .035 & $1.302^{\mathrm{b}}$ & 3 & 107 & .278 & .339 \\
\hline \multicolumn{7}{|c|}{ Factor $1^{*}$ inotropic use } \\
\hline
\end{tabular}

* Denotes interaction.

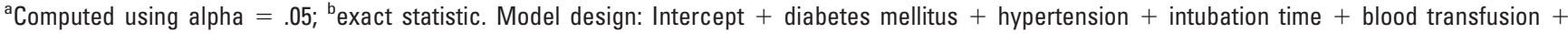
compromised; left ventricular (LV) function + inotropic use + cardiopulmonary bypass (CPB) within subjects design: Factor 1: Serum creatinine levels: preoperative and postoperative days 1, 5, and 15; $d f$, degrees of freedom.

erative renal failure. The majority of factors associated with increased risk of developing ARF are patient related and beyond the clinician's control, the exception being use or nonuse of CPB.

Although serum creatinine alone is the most widely used assay to measure the presence and progression of chronic kidney disease, equations based on serum creatinine level, age, sex, and other variables are more sensitive at predicting changes in renal function. ${ }^{26}$ The Cockcroft-Gault equation was developed to estimate creatinine clearance ${ }^{27}$ but has been used to estimate GFR with relatively good precision. ${ }^{28}$

Recently, several equations have been developed using the MDRD study to estimate GFR directly. ${ }^{29}$ Serum creatinine level is not as accurate as GFR to assess renal function. ${ }^{13} \mathrm{We}$ also found in our study that, preoperatively, $30 \%$ of patients with a normal level of serum creatinine $(\leq 1.29$ $\mathrm{mg} / \mathrm{dL}$ ) were in stage 3 of chronic kidney disease (the K/DOQI CKD 5-stage classification). ${ }^{23}$

With the resurgence of interest in CABG without the use of $\mathrm{CPB}$, there were a few observational comparative studies published on CABG with or without using $\mathrm{CPB}$ in patients with preoperative non-dialysis-dependent renal insufficiency. All these studies showed that OPCAB reduces in-hospital morbidity and likelihood of ARF in patients with preoperative non-dialysis-dependent renal insufficiency. ${ }^{14-18}$ Yet other nonrandomized studies failed to show the renoprotective effect of the off-pump technique in non-dialysis-dependent renal insufficiency where serum creatinine levels were used to define renal insufficiency. ${ }^{19-22}$

$\mathrm{CPB}$ represents a specific risk factor during cardiac surgery. The injurious effect of $\mathrm{CPB}$ on renal function is caused by several mechanisms including nonpulsatile perfusion, renal hypoperfusion, hypothermia, and increased levels of circulating catecholamines, cytokines, and free hemoglobin. ${ }^{30,31} \mathrm{CPB}$ induces transient renal injury in patients undergoing cardiac surgical procedures as evidenced by decreased tubular function and increased levels of markers of glomerular and tubular damage. Free plasma hemoglobin, elastase and endothelin, and free radicals including superoxide, hydrogen peroxide, and hydroxyl radicals may be generated during CPB and may determine injury in the renal brush-border membrane. ${ }^{32}$ The effect, in turn, can produce renal dysfunction, especially in the presence of additional risk factors like pre-existing renal dysfunction, diabetes, and hypertension. ${ }^{33}$ Changes in these parameters were essentially confined to the intraoperative and immediate postoperative periods and returned to baseline levels within 2 days. ${ }^{4}$ It was also documented by Karkouti and colleagues $^{34}$ that there was an independent association between the degree of hemodilution during CPB and perioperative ARF necessitating dialysis support.

The off-pump technique for coronary revascularization was popularized in the early 1990s and led to investigation as to whether the avoidance of CPB altogether would minimize postoperative renal injury and/or insufficiency. Use of beating heart techniques means maintenance of pulsatile flow and no exposure to the extracorporeal circuit, with an anticipated reduction in the inflammatory cytokine response, normothermia, and a decreased requirement for vasoconstrictor administration to maintain target mean arterial pressure. ${ }^{20}$ However, some of the previously published retrospective analyses, which assessed changes in 
TABLE 4B. Multivariate tests for changes in glomerular filtration rate

\begin{tabular}{|c|c|c|c|c|c|c|}
\hline Effect & Value & $\mathbf{F}$ & Hypothesis df & Error $d f$ & Sig. & Observed power $^{\mathrm{a}}$ \\
\hline \multicolumn{7}{|l|}{ Factor 1} \\
\hline Pillai's trace & .087 & $5.171^{b}$ & 2 & 108 & .007 & .818 \\
\hline \multicolumn{7}{|c|}{ Factor $1 *$ diabetes } \\
\hline Pillai's trace & .041 & $2.301^{b}$ & 2 & 108 & .105 & .458 \\
\hline \multicolumn{7}{|c|}{ Factor $1 *$ hypertension } \\
\hline Pillai's trace & .005 & $.267^{\mathrm{b}}$ & 2 & 108 & .767 & .091 \\
\hline \multicolumn{7}{|c|}{ Factor $1 *$ intubation time } \\
\hline Pillai's trace & .001 & $.063^{b}$ & 2 & 108 & .939 & .059 \\
\hline \multicolumn{7}{|c|}{ Factor $1 *$ blood transfusion } \\
\hline Pillai's trace & .025 & $1.394^{b}$ & 2 & 108 & .253 & .294 \\
\hline \multicolumn{7}{|c|}{ Factor $1 *$ compromised LV function } \\
\hline Pillai's trace & .056 & $3.207^{b}$ & 2 & 108 & .044 & .602 \\
\hline \multicolumn{7}{|c|}{ Factor $1 *$ inotropic usage } \\
\hline Pillai's trace & .026 & $1.417^{b}$ & 2 & 107 & .247 & .298 \\
\hline \multicolumn{7}{|l|}{ Factor 1 * CРB } \\
\hline Pillai's trace & .191 & $12.712^{b}$ & 2 & 108 & .000 & .996 \\
\hline
\end{tabular}

*Denotes interaction.

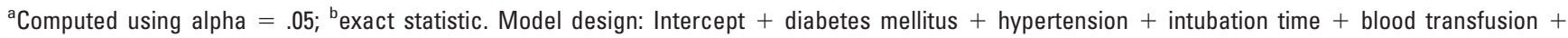
compromised left ventricular (LV) function + inotropic usage + cardiopulmonary bypass (CPB) within subjects design: Factor 1: Glomerular filtration rate: preoperative and postoperative days 1 and 5 ; $d f$, degrees of freedom.

renal function using serum creatinine levels, have failed to demonstrate a significant renoprotective effect of the offpump technique. ${ }^{21,22}$ The study by Stallwood and colleagues ${ }^{8}$ showed that $\mathrm{CPB}$ is associated with a significantly increased risk of ARF after isolated CABG.

Although early reports of subtle reduction in renal insult and promising findings from nonrandomized outcome studies hinted at benefit, many nonrandomized studies including a meta-analysis failed to confirm the advantage. ${ }^{35}$ However, many such studies ignored the question most important to the clinicians: does off-pump surgery confer benefit to the patient with non-dialysis dependent renal insufficiency?

To the best of our knowledge, there has been no randomized study published comparing the effect of off-pump and on-pump CABG in patients with non-dialysis dependent renal insufficiency defined by GFR as well as serum creatinine.

In our study, $30 \%$ of patients with preoperative normal serum creatinine levels $(\leq 1.29 \mathrm{mg} / \mathrm{dL}$ ) were found to be in stage 3 of chronic kidney disease by GFR criteria (GFR $\leq$ $60 \mathrm{~mL} \cdot \mathrm{min}^{-1} \cdot 1.73 \mathrm{~m}^{-2}$ ). It indicates that GFR is a more sensitive indicator for evaluating renal function preoperatively than serum creatinine estimation. Although Wijeysundera and colleagues ${ }^{36}$ proposed a simple calculated creatinine clearance in preoperative assessment, which might improve identification of patients at risk of needing postoperative renal replacement therapy, the estimation of GFR is more sensitive in predicting requirement of renal replacement therapy in patients with non-dialysis dependent renal insufficiency. Further, this study showed a significant rise in serum creatinine levels at postoperative day 1 and day 5 in the $\mathrm{CPB}$ group compared with the OPCAB group $(P=$ $.001)$ and a statistically significant fall in GFR in the CPB group compared with the OPCAB group $(P<.007)$.

It is also observed that significantly more patients with diabetes showed further elevation of serum creatinine in the postoperative period in the on-pump group than in the off-pump group $(P<.002)$. These findings suggest that the off-pump technique is more renoprotective in patients with non-dialysis dependent renal insufficiency.

More hypertensive patients undergoing CABG showed deterioration in renal function (rise in serum creatinine and fall in GFR) in the postoperative period in the on-pump group than in the off-pump group (serum creatinine, $P<$ .011; GFR, $P<.029$ ).

In patients with compromised LV function, the fall in GFR was also significant in the CBP group compared with the OPCAB group $(P<.032)$ whereas the rise in serum creatinine levels was not significant $(P<.10)$.

In our study, repeated-measures analysis of variance and covariate analysis showed the use of CPB is significantly associated with adverse renal outcome. In addition, the effects of inotropic use, blood transfusion, intubation time, and the presence of diabetes mellitus, hypertension, and compromised LV function on renal outcomes as measured by serum creatinine and MDRD GFR are studied, introducing all these variables as covariates in the repeated-measures analysis. Diabetes mellitus has emerged as a significant covariate (by serum creatinine levels) and compromised LV function as a significant covariate (by 
GFR criteria), and all other covariates were not statistically significant.

A couple of randomized trials of evaluating $N$-acetylcysteine to prevent renal dysfunction in high-risk patients undergoing CABG have shown that $N$-acetylcysteine was ineffective in preventing renal dysfunction. ${ }^{37}$ However, we chose to use $N$-acetylcysteine for both groups of our patients with non-dialysis dependent renal insufficiency because, in renal diseases, $N$-acetylcysteine was initially tested in an experimental model of ischemic ARF, resulting in protective effects on renal function and structure. ${ }^{38}$

A systematic review and meta-analysis of randomized clinical trials conducted on the effect of aprotinin on clinical outcomes in $\mathrm{CABG}$ revealed the concern that aprotinin therapy is associated with increased mortality, myocardial infarction, or renal failure risk, but this concern is not supported by the data published. In our study, only 2 patients in the on-pump group received aprotinin who had excessive mediastinal bleeding due to generalized oozing, despite adequate heparin neutralization, and they did not show important $(\geq 20 \%)$ deterioration in renal function either by serum creatinine or GFR criteria. ${ }^{39}$

This randomized study confirmed the renoprotective effect of OPCAB of the previously published observational studies that used serum creatinine level alone to assess preoperative renal function. ${ }^{8,14-18}$ Furthermore, we found that patients who have diabetes, hypertension, and compromised LV function fared worse with the on-pump technique. This study also showed that GFR is a more sensitive investigation to assess renal function in the preoperative period. By evaluating renal function preoperatively using GFR in patients undergoing CABG, one would be able to detect compromised renal function even in the presence of normal serum creatinine levels. This knowledge enables the operating team to take necessary measures to prevent further deterioration in renal function by preferentially using the off-pump technique for surgical revascularization.

\section{Limitations of the Study}

Our study is a single-center study and is limited by the number of patients enrolled in the study. It is also limited by lack of data on the progression of renal impairment during the follow-up period.

\section{Conclusions}

$\mathrm{OPCAB}$ is more renoprotective for patients with non-dialysis-dependent renal insufficiency. The renoprotective effect is more pronounced in patients with diabetes, hypertension, and compromised LV function. We suggest that all patients undergoing $\mathrm{CABG}$ may need preoperative assessment of renal function by GFR in addition to serum creatinine levels to stratify the risk for postoperative ARF and to optimize measures for renal preservation during surgical myocardial revascularization.

We sincerely thank A. Nadamuni Naidu, MSc (stat), Head, Department of Statistics (Rtd), National Institute of Nutrition, ICMR, Hyderabad, India, and B. R. Sajja, MSc, PhD, of the University of Texas Medical Center at Houston, Texas, for statistical advice and statistical analysis for our study. We also thank Subba Rao Nagalla, Bcom, of CARE Foundation, Hyderabad, for the help in preparing the manuscript.

\section{References}

1. Hilberman M, Derby GC, Spencer RJ, Stinson EB. Sequential pathophysiological changes characterizing the progression from renal dysfunction to acute renal failure following cardiac operation. $J$ Thorac Cardiovasc Surg. 1980;79:838-44.

2. Zanardo G, Michielon P, Paccagnella A, Rosi P, Calo M. Salandi V, et al. Acute renal failure in the patients undergoing cardiac operation: prevalence, mortality rate, and main risk factors. J Thorac Cardiovasc Surg. 1994;107:489-495.

3. Sirivella S, Gielchinksy I, Parsonnet V. Mannitol, furosemide, and dopamine infusion in postoperative renal failure complicating cardiac surgery. Ann Thorac Surg. 2000;69:501-6.

4. Loef BG, Epema AH, Navis G, Ebels T, van Peveren W, Henning RH. Off-pump coronary revascularization attenuates transient renal damage compared with on-pump coronary revascularization. Chest. 2002;121: 1190-4.

5. Chertow GM, Lazarus JM, Christiansen CL, Hook EF, Hammermeister KE, Grover F, et al. Preoperative renal risk stratification. Circulation. 1997;95:878-84.

6. Chertow GM, Levy EM, Hammermeister KE, Daley J. Independent association between acute renal failure and mortality following cardiac surgery. Am J Med. 1998;104;343-8.

7. Mangano CM, Diamondstone LS, Ramsay JG, Aggarwal A, Herskowitz A, Mangano DT. Renal dysfunction after myocardial revascularization: risk factors, adverse outcomes, and hospital resource utilization. The Multicenter Study of Perioperative Ischemia Research Group. Ann Intern Med. 1998;128:194-203.

8. Stallwood MI, Grayson AD, Mills K, Scawn ND. Acute renal failure in coronary artery bypass surgery: independent effect of cardiopulmonary bypass. Ann Thorac Surg. 2004;77:968-72.

9. Rao V, Weisel RD, Buth KJ, Cohen G, Borger MA, Shiono N, et al. Coronary artery bypass grafting in patients with non-dialysis dependent renal insufficiency. Circulation. 1997;96(9 Suppl II-):38-44.

10. Durmaz I, Buket S, Atay Y, Yagdi T, Ozbaran M, Boga M, et al. Cardiac surgery with cardiopulmonary bypass in patients with chronic renal failure. J Thorac Cardovasc Surg. 1999;118:306-15.

11. Anderson RJ, O’Brien M, Mawhinney S, Villanueva CB, Moritz TE, Sethi GK, et al. Renal failure predisposes patients to adverse outcome after coronary artery bypass surgery. VA Cooperative Study \#5. Kidney Int. 1999;55:1057-62

12. Weersinghe A, Hornick P, Taylor K, Ratnatunga C. Coronary artery bypass grafting in non-dialysis-dependent mild-to-moderate renal dysfunction. J Thorac Cardiovasc Surg. 2001;121:1083-9.

13. Bostom AG, Kronenberg F, Ritz E. Predictive performance of renal function equations for patients with chronic kidney disease and normal serum creatinine levels. J Am Soc Nephrol 2002;13:2140-4.

14. Ascione R, Nason G, Al-Ruzzeh, Ko C, Ciulli F, Angelini GD. Coronary revascularization with or without cardiopulmonary bypass in patients with preoperative non dialysis-dependent renal insufficiency. Ann Thorac Surg. 2001;72:2020-5.

15. Sabik JF, Gillinov AM, Blackstone EH, Vacha C, Houghtaling PL, Navia J, et al. Does off-pump coronary surgery reduce morbidity and mortality. J Thorac Cardiovasc Surg. 2002;124:698-707.

16. Puskas JD, Cheng D, Knight J, Angelini G, De Cannier D, Dieghler A, et al. Off-pump versus conventional coronary artery bypass grafting: a meta-analysis and consensus statement from the 2004 ISMICS consensis conference. Innovation. 2005;1:3-27. 
17. Arom KV, Flavin TF, Emery RW, Kshettry VR, Janey PA, Petersen RJ. Safety and efficacy of off-pump coronary artery bypass grafting. Ann Thorac Surg. 2000;69:704-10.

18. Ascione R, Lloyd CT, Underwood MJ, Gomes WJ, Angelini GD. On-pump versus off-pump coronary revascularization: evaluation of renal function. Ann Thorac Surg. 1999;68:493-98.

19. Schwann N, Horrow J, Strong M, Chamchad D, Guerraty A, Wechsler A. Does off-pump coronary artery bypass reduce the incidence of clinically evident renal dysfunction after multivessel myocardial revascularization.Anesth Analg. 2004;99:959-64.

20. Gamoso MG, Phillips-Bute B, Landolfo KP, Newman MF, Stafford Smith M. Off-pump versus on-pump coronary artery bypass surgery and post-operative renal dysfunction. Anesth Analg. 2000;91:1080-4.

21. Zamvar VY, Khan NU, Madhavan A, Kulatilake N, Butchart EG. Clinical outcomes in coronary artery bypass graft surgery: comparing off-pump and on-pump techniques. Heart Surg Forum. 2002;5:109-13.

22. Chukwuemeka A, Weisel A, Maganti M, Nette AF, Wijeysundera DN, Beattie WS, et al. Renal dysfunction in high-risk patients after onpump and off-pump coronary artery bypass surgery: a propensity score analysis. Ann Thorac Surg. 2005;80:2148-53.

23. National Kidney Foundation. K/DOQI clinical practice guidelines to define chronic kidney disease: evaluation, classification and stratification. Am J Kidney Dis. 2002;39(Suppl 1):S1-266.

24. Mehta RL, Chertow GM, Acute renal failure definitions and classification: time for change? J Am Soc Nephrol. 2003;14:2178-87.

25. Sajja LR, Mannam G, Sompalli S, Reddy KV, Ravirala BR, Raju BS, et al. Does multi- vessel off-pump coronary artery bypass grafting reduce postoperative morbidity compared to on-pump CABG? Ind J Thorac Cardiovasc Surg. 2004;20:173-7.

26. Levey AS. Measurement of renal function in chronic renal disease. Kidney Int. 1990;38:167-84.

27. Cockcroft DW, Gault MH. Prediction of creatinine clearance from serum creatinine. Nephron. 1976;16:31-5.

28. Gault MH, Longerich LL, Harnett JD, Wesolowski C. Predicting glomerular function from adjusted serum creatinine. Nephron. 1992; 62:249-56.

29. Levey AS, Greene T, Kusek JW, Beck GJ, MDRD Study Group. A simplified equation to predict glomerular filtration rate from serum creatinine. J Am Soc Nephrol. 2000;11:155A(abstract A0828).

30. Ramsay JG. The respiratory, renal and hepatic systems: effect of cardiac surgery and cardiopulmonary bypass. In: Mora CT, editor. Cardiopulmonary bypass. New York: Springer-Verlag; 1995. p. 147168.

31. Hickey PR, Buckley MJ, Philbin DM. Pulsatile and nonpulsatile cardiopulmonary bypass: review of a counterproductive controversy. Ann Thorac Surg. 1983;36:720-7.

32. Regragui IA, Izzat MB, Birdi I, Lapsley M, Bryan AJ, Angelini GD. Cardiopulmonary bypass perfusion temperature does not influence preoperative renal function. Ann Thorac Surg. 1995;60:160-4.

33. Hilberman M, Myer BD, Carrie BJ, Derby G, Jamison RL, Stinson EB, et al. Acute renal failure following cardiac surgery. $J$ Thorac Cardiovasc Surg. 1979;77:880-8.

34. Karkouti K, Beattie WS, Wijeysundera DN, Rao V, Chan C, Dattilo $\mathrm{KM}$, et al. Hemodilution during cardiopulmonary bypass is an independent risk factor for acute renal failure in adult cardiac surgery. J Thorac Cardiovasc Surg. 2005;126:391-400.

35. Cheng DC, Bainbridge D, Martin JE, Novick RJ. Does off-pump coronary artery bypass reduce mortality, morbidity and resource utilization when compared with conventional coronary artery bypass? A meta analysis of randomized trials. Anesthesiology. 2005;102:188-203.

36. Wijeysundera DN, Karkouti K, Beattie WS, Rao V, Ivanov J. Improving the identification of patients at risk of postoperative renal failure after cardiac surgery. Anesthesiology. 2006;104:65-72.

37. Burns KE, Chu MW, Novic RJ, Fox AS, Gallo K, Martin CM, et al. Perioperative $\mathrm{N}$-acetylcysteine to prevent renal dysfunction in high risk patients undergoing $\mathrm{CABG}$ surgery: a randomized controlled trial. JAMA. 2005;294:342-50.

38. DiMari J, Megyesi J, Udvarhelyi N, Price P, Davis R, Safirstein R. $\mathrm{N}$-acetylcysteine ameliorates ischemic renal failure. Am J Physiol. 1997;272:F292-8
39. Sedrakyan A, Treasure T, Elefteriades JA. Effect of aprotinin on clinical outcomes in coronary artery bypass graft surgery: a systematic review and meta-analysis of randomized clinical trials. J Thorac Cardiovasc Surg. 2004;128:442-8.

\section{Discussion}

Dr John D. Puskas (Atlanta, Ga). My congratulations to you and your colleagues from Hyderabad for enrolling 116 patients in 16 months in a randomized surgical trial. That may be a world record for a single center.

Your study has again demonstrated, as others have, that OPCAB is associated with a significant decrease in inotrope dependence, transfusion, chest tube drainage, and ventilation time. You have also found a trend toward a decrease in death and postoperative hemodialysis, but your primary end point was to focus on the increase in serum creatinine and decline in GFR after CPB, and you demonstrated a benefit for OPCAB that was greatest in diabetic patients and in hypertensive patients. I have several questions for you.

First, how well did you control the mean CPB perfusion pressures during the on-pump cases, and how did that compare with the mean arterial pressures during off-pump surgical procedures? In other words, is it a matter of perfusion of the body during these two operations or is it something else related to the pump that would explain your differences?

Dr Sajja. Thank you, Dr Puskas, for your comments and questions. In the on-pump group, we maintained the systemic mean arterial pressure at around 65 to $70 \mathrm{~mm} \mathrm{Hg}$, while in the off-pump group, most of the time the mean pressure was about 70 to $75 \mathrm{~mm} \mathrm{Hg}$. Usually, when we revascularize the anterior vessels, the mean pressure is much higher than what we maintain on the pump.

Dr Puskas. You found after surgery that there was an increased dependence on inotropes in the on-pump group relative to the off-pump group. Were you able to examine those subsets of patients who required inotropes in both groups and compare renal outcomes between these subgroups? In other words, is it a matter of inotrope dependence after the pump run that explains the difference in renal outcomes or is it something else?

Dr Sajja. We have analyzed the inotropic requirements between the two groups and found a significant number of patients require inotropes in the on-pump group, but we have not analyzed whether inotropic requirement is an independent predictor of renal failure or not. The myocardial protection that occurred during off-pump is better than on-pump CABG.

Dr Richard J. Shemin (Boston, Mass). I think this paper is also important in that you emphasize that $30 \%$ of patients with normal serum creatinine values actually have renal disease. But my real question is, in the on-pump group compared with the off-pump group, how many conversions did you have from off-pump to on-pump and did you analyze the data on an intent-to-treat basis if you did have such conversions?

Dr Sajja. Fortunately, none of the patients in this study in the off-pump group needed conversion to CPB. We have been doing the off-pump surgery since 1996 and the technique has been standardized.

Dr Ralph J. Damiano (St Louis, Mo).I would like to echo the congratulations from the other discussants, Dr Sajja, on a wellperformed randomized study. My question is really a follow-up on Dr Puskas's question. Did you look at the use of nephrotoxic drugs between each group? In particular, was aprotinin used more often in the on-pump group? How about other drugs like alpha agonists, 
which clearly could have an adverse effect on renal function? Could this potentially explain the difference as opposed to the use of the pump itself?

Finally, could you share with us whether the advantages of the off-pump technique also extend to the dialysis-dependent group in your experience?

Dr Sajja. Thank you for your questions. Regarding the use of nephrotoxic drugs, we have avoided using aminoglycosides and other nephrotoxic drugs in all of these patients, whether they are treated on-pump or off-pump, but in all these patients we have given $N$-acetylcysteine preoperatively and for 5 days postoperatively.

We do not have much experience with dialysis-dependent patients undergoing $\mathrm{CABG}$, only a couple of cases; therefore, I cannot comment on the advantages of the off-pump technique in this subset of patients.

Dr Damiano. Do you use aprotinin in the on-pump group?

Dr Sajja. Only 2 patients received aprotinin in the on-pump group and none in the off-pump group. The use of aprotinin is not common in our institution.

\section{Interactive eLearning Activities http://learning.ctsnet.org}

The Joint Council on Thoracic Surgery Education was pleased to introduce a series of unique eLearning activities to CTSNet users at the AATS annual meeting in Philadelphia. Sponsored by several cardiothoracic surgical groups, this exciting new educational tool contains narrated videos of actual surgical procedures followed by a series of questions and an evaluation to earn Continuing Medical Education credit.

* Diagnosis and Management of Complications of Mitral Valve Repair

* Off Pump Coronary Artery Bypass

* OPCAB Debriefing

* Pediatric Cardiopulmonary Bypass Emergency Situations

\section{Experience these new educational tools today and provide us with your feedback. Go to: http://learning.ctsnet.org}

William E. Baumgartner, Chair

Joint Council on Thoracic Surgery Education

$$
\text { Sponsored By: }
$$

American Association for Thoracic Surgery

The Society of Thoracic Surgeons

European Association for Cardio-Thoracic Surgery

Children's Memorial Hospital 


\section{E-Anesthesia Technique*}

E-The anesthetic technique was standardized for all patients. This consisted of intravenous anesthesia with propofol infusion at $3 \mathrm{mg}$ $\cdot \mathrm{kg}^{-1} \cdot \mathrm{h}^{-1}$. The neuromuscular blockade was achieved by 0.1 to $0.15 \mathrm{mg} / \mathrm{kg}$ vecuronium bromide and lungs ventilated to normocapnea with medical air and oxygen (45\%-50\%) without positive end-expiratory pressure. In the on-pump group, phenylephrine or nitroglycerin was used to maintain a systemic mean pressure of 60 to $70 \mathrm{~mm} \mathrm{Hg}$. In the off-pump group, a mean systemic arterial pressure of $65 \mathrm{~mm} \mathrm{Hg}$ or above was maintained with increments of dobutamine or norepinephrine or volume as directed by the hemodynamic condition.

\section{E-Heparin and Protamine Management*}

E-In the on-pump group, heparin was given at a dose of $300 \mathrm{IU} / \mathrm{kg}$ to achieve activated clotting times of 450 seconds or above before institution of CPB. The activated clotting time was monitored during the bypass period (every 30 minutes) and additional heparin was administered if required. In the off-pump group, $100 \mathrm{IU} / \mathrm{kg}$ of heparin was administered before the start of the first distal anastomosis to achieve an activated clotting time of 250 to $350 \mathrm{sec}-$ onds. On completion of all anastomoses, protamine was given to reverse the effect of heparin and return the activated clotting time to preoperative levels.

\section{E-Surgical Technique ${ }^{\dagger}$}

E-All incision and closure techniques were the same in both groups. No cell salvage device was used during these procedures. The distal anastomosis for the left internal thoracic artery graft was constructed with 8-0 polypropylene continuous suture, and for the saphenous vein and radial artery grafts 7-0 polypropylene suture was used. All the proximal anastomoses of radial artery grafts were constructed with 7-0 polypropylene suture and those of the saphenous vein grafts were constructed with 6-0 polypropylene suture.

\section{E-Definitions ${ }^{\dagger}$}

E-Patients were defined as having diabetes mellitus if they were taking insulin or oral hypoglycemic agents, and as having hypertension if they were taking antihypertensive medication. A coronary artery was defined as significantly obstructed if the luminal diameter was narrowed at least $50 \%$ as assessed visually by the cardiologist performing the coronary angiography. LVEF was assessed by using 2-dimensional echocardiography, and LV function was categorized as normal, fair, or poor according to an LVEF of $50 \%$ or more, $40 \%$ to $49 \%$, or $39 \%$ or less, respectively. Postoperative blood loss was defined as total chest tube drainage, and neurologic complications included permanent and transient stroke. Pulmonary complications included chest infection, ventilation failure, reintubation, and tracheostomy.

\section{E-Outcome Data ${ }^{\dagger}$}

E-Intraoperative data and postoperative data were entered prospectively into our database. In-hospital mortality was defined as any death occurring within 30 days of operation. Heart rate, rhythm, and ST-segment changes were continuously displayed in a monitor inclusive of an automated detector of segment elevations and arrhythmias during the first 48 hours postoperatively (Agilent $\mathrm{V}$ 24C; Hewlett-Packard, Boebinger, Germany). Perioperative myocardial infarction, ST-segment changes, pacing, arrhythmias, and inotropic requirement were recorded. Renal complications including further rise in serum creatinine level and fall in GFR and ARF necessitating hemodialysis were recorded. 
TABLE E1. Means and repeated-measures analysis of results of preoperative and postoperative values in the subset of patients with diabetes

\begin{tabular}{|c|c|c|c|c|c|c|c|}
\hline \multirow[b]{2}{*}{ CPB } & \multirow[b]{2}{*}{$\mathbf{N}$} & \multirow[b]{2}{*}{ Mean } & \multirow[b]{2}{*}{ SD } & \multirow[b]{2}{*}{ Geometric mean } & \multicolumn{3}{|c|}{ ANOVA results } \\
\hline & & & & & Significant effect power & $\mathbf{F}$ & $P$ \\
\hline \multicolumn{8}{|l|}{ S. creatinine preop } \\
\hline With CBP & 32 & 1.497 & .5986 & 1.427 & & & \\
\hline \multicolumn{8}{|l|}{ S. creatinine POD1 } \\
\hline Without CBP & 33 & 1.709 & .4946 & 1.658 & & & \\
\hline S. creatinine POD 5 & & & & & Time & 111.2 & $<.0001 .000$ \\
\hline Without CBP & 33 & 1.785 & .8228 & 1.658 & $\mathrm{CBP} \times$ time & 9.07 & $<.0000 .997$ \\
\hline With CBP & 32 & 2.027 & 1.0750 & 1.862 & & & \\
\hline \multicolumn{8}{|l|}{ S. creatinine POD 15} \\
\hline Without CBP & 33 & 1.482 & .4908 & 1.431 & & & \\
\hline With CBP & 32 & 1.531 & .5025 & 1.470 & & & \\
\hline Without CBP & 33 & 47.6788 & 16.76566 & 44.3771 & Time & 14.08 & $<.0000 .998$ \\
\hline With CBP & 32 & 41.7712 & 17.29179 & 38.5223 & $\mathrm{CBP} \times$ time & 11.47 & $<.0000 .990$ \\
\hline \multicolumn{8}{|l|}{ MDRD GFR POD 5} \\
\hline Without CBP & 33 & 52.3109 & 11.30933 & 51.1333 & & & \\
\hline With CBP & 32 & 46.4357 & 13.81849 & 44.6585 & & & \\
\hline
\end{tabular}

The log-transformed serum creatinine/GFR values were subjected to statistical analysis using repeated-measures analysis of variance. $C P B$, Cardiopulmonary bypass; MDRD GFR, Modification of Diet in Renal Disease equation glomerular filtration rate; $P O D$, postoperative day; time, changes with duration of time during postoperative period; $C P B \times$ time, interaction of the procedure with or without CPB $\times$ time; $S D$, standard deviation. 
TABLE E2. Means and repeated measures analysis of results of preoperative and postoperative values in subset of patients with hypertension

\begin{tabular}{|c|c|c|c|c|c|c|c|}
\hline \multirow[b]{2}{*}{ CPB } & \multirow[b]{2}{*}{$\mathbf{N}$} & \multirow[b]{2}{*}{ Mean } & \multirow[b]{2}{*}{ SD } & \multirow[b]{2}{*}{ Geometric mean } & \multicolumn{3}{|c|}{ ANOVA results } \\
\hline & & & & & Significant effect power & $\mathbf{F}$ & $P$ \\
\hline \multicolumn{8}{|l|}{ S. creatinine preop } \\
\hline Without CBP & 37 & 1.459 & .5036 & 1.399 & & & \\
\hline With CBP & 46 & 1.522 & .5970 & 1.448 & & & \\
\hline \multicolumn{8}{|l|}{ S. creatinine POD 1} \\
\hline Without CBP & 37 & 1.670 & .5206 & 1.611 & & & \\
\hline With CBP & 46 & 1.980 & .8248 & 1.880 & & & \\
\hline S. creatinine POD 5 & & & & & Time & 52.59 & $<.0001 .000$ \\
\hline Without CBP & 37 & 1.781 & .8498 & 1.645 & $\mathrm{CBP} \times$ time & 4.95 & $<.0030 .899$ \\
\hline With CBP & 46 & 2.014 & .9543 & 1.873 & & & \\
\hline \multicolumn{8}{|l|}{ S. creatinine POD 15} \\
\hline Without CBP & 37 & 1.478 & .4911 & 1.426 & & & \\
\hline With CBP & 46 & 1.533 & .4341 & 1.485 & & & \\
\hline \multicolumn{8}{|l|}{ MDRD GFR preop } \\
\hline Without CBP & 37 & 50.765 & 9.8232 & 49.564 & & 20.14 & $<.0000 .998$ \\
\hline With CBP & 46 & 51.632 & 9.8995 & 50.305 & & 8.11 & $<.0000 .990$ \\
\hline \multicolumn{8}{|l|}{ MDRD GFR POD 1} \\
\hline Without CBP & 37 & 49.5938 & 17.37142 & 46.0118 & Time & & \\
\hline With CBP & 46 & 40.2039 & 15.33329 & 37.4183 & $\mathrm{CBP} \times$ time & & \\
\hline \multicolumn{8}{|l|}{ MDRD GFR POD 5} \\
\hline Without CBP & 37 & 53.5505 & 12.50092 & 52.1110 & & & \\
\hline With CBP & 46 & 44.7218 & 12.08288 & 43.1542 & & & \\
\hline
\end{tabular}

The log-transformed serum creatinine/GFR values were subjected to statistical analysis using repeated-measures analysis of variance. $C P B$, Cardiopulmonary bypass; MDRD GFR, Modification of Diet in Renal Disease equation glomerular filtration rate; $P O D$, postoperative day; time, changes with duration of time during postoperative period; $C P B \times$ time, interaction of the procedure with or without $C P B \times$ time; $S D$, standard deviation. 